Western University

Scholarship@Western

Chemistry Publications

Chemistry Department

7-16-2018

\title{
Controlled Polymerization of Ethyl Glyoxylate Using Alkyllithium and Alkoxide Initiators
}

Amir Rabiee Kenaree

Western University

Elizabeth R. Gillies

Western University, egillie@uwo.ca

Follow this and additional works at: https://ir.lib.uwo.ca/chempub

Part of the Chemistry Commons

Citation of this paper:

Rabiee Kenaree, Amir and Gillies, Elizabeth R., "Controlled Polymerization of Ethyl Glyoxylate Using Alkyllithium and Alkoxide Initiators" (2018). Chemistry Publications. 105.

https://ir.lib.uwo.ca/chempub/105 


\title{
Controlled Polymerization of Ethyl Glyoxylate Using
}

\section{Alkyllithium and Alkoxide Initiators}

\author{
Amir Rabiee Kenaree ${ }^{\dagger}$ and Elizabeth R. Gillies* ${ }^{* \dagger}$
}

$\dagger$ Department of Chemistry, The University of Western Ontario, 1151 Richmond St., London, Ontario, Canada N6A 5B7.

*Department of Chemical and Biochemical Engineering, The University of Western Ontario, 1151 Richmond St., London, Ontario, Canada N6A 5B9.

\section{For Table of Contents use only

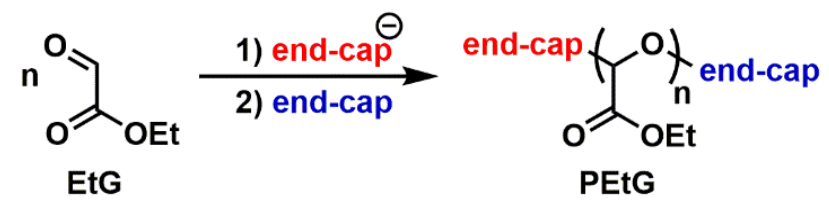

\begin{abstract}
The synthesis of poly(ethyl glyoxylate)s (PEtGs) by anionic polymerization was explored. PEtGs are a subclass of stimuli-responsive self-immolative polymers with promising properties for applications as coatings, sensors, and drug delivery vehicles. In this report, a new purification procedure for the preparation of highly pure ethyl glyoxylate (EtG), suitable for anionic
\end{abstract}


polymerization reactions, and the first successful examples of controlled polymerization of EtG are described. $n$-BuLi, $\mathrm{PhLi}$, and $t$-BuLi were employed as initiators under different experimental conditions and their behavior was examined using NMR spectroscopy, size exclusion chromatography, and thermal analysis to develop an optimized procedure. As functional alkoxide initiators, propargyl alkoxide was employed in optimization studies and poly(ethylene glycol) (PEG) dialkoxide was utilized for the direct synthesis of PEtG-PEG-PEtG copolymers. The new polymerization method revealed many features of controlled polymerization reactions, yielding PEtGs with predictable molar masses and relatively low dispersity values.

\section{INTRODUCTION}

Self-immolative polymers (SIPs) ${ }^{1-5}$ are an intriguing class of stimuli-responsive polymers ${ }^{6-11}$ that undergo a controlled end-to-end depolymerization process when a stimulus such as light, ${ }^{12-14}$ heat, ${ }^{15}$ acid,,${ }^{16}$ enzyme, ${ }^{17,18}$ redox agent, $,{ }^{19}, 20$ or specific ion ${ }^{21,22}$ triggers their depolymerization by removing their end-caps. The most widely investigated backbones have been polycarbamates ${ }^{3,5}$, ${ }^{23-25}$ and poly(phthalaldehyde)s. ${ }^{21,26-32}$ The desirable properties of SIPs have been exploited in a variety of research fields including sensors, ${ }^{5,33}, 34$ self-powered microscale pumps, ${ }^{35}$ shapechanging materials, ${ }^{31}$ nanolithography, ${ }^{32,36,37}$ and drug delivery. ${ }^{14,23,38,39-41}$

Poly(ethyl glyoxylate) (PEtG) was first synthesized by Burel and coworkers, who showed that end-capping PEtG with phenyl isocyanate was an effective way to stabilize it with respect to spontaneous depolymerization and thus provided a method for the synthesis of non-stimuliresponsive PEtGs. ${ }^{42}$ They then investigated the hydrolysis behavior of PEtGs in aqueous media, and demonstrated that degradation proceeded by a variety of mechanisms, leading to ethanol and 
glyoxylic acid hydrate as products. ${ }^{43,44}$ These degradation products were found to be non-toxic in a Caenorhabditis elegans (invertebrate) model. ${ }^{45}, 46$ Our group incorporated stimuli-responsive end-groups to enable triggered depolymerization of PEtG and also polymerized different glyoxylate monomers to afford a variety of triggerable polyglyoxylate homopolymers and copolymers. ${ }^{40,47,48}$ We later showed proof of concept for the use of self-immolative PEtG and its block copolymers with poly(ethylene glycol) (PEG) in applications including drug delivery ${ }^{39,} 40$ and smart packaging sensors. ${ }^{49}$

In all of the above studies, PEtGs were prepared by the proton-transfer-mediated polymerization of ethyl glyoxylate (EtG). In this method, residual EtG hydrate species serve as initiators and the subsequent nucleophilic addition reactions are facilitated by a proton-transfer agent such as $\mathrm{NEt}_{3}$ (Scheme 1a). This mechanism has been suggested based on ${ }^{1} \mathrm{H}$ NMR spectroscopic analyses wherein two end-groups per polymer chain were observed. ${ }^{42,}{ }^{47}$ This method has often been referred to as "anionic polymerization", but here we prefer the use of "proton-transfer-mediated polymerization" because the former may give the wrong impression that the propagating species are always negatively charged $\left(\mathrm{pK}_{\mathrm{a}}\right.$ of $\mathrm{HNEt}_{3}{ }^{+}<<\mathrm{pK}_{\mathrm{a}}$ of $\left.\mathrm{ROH}\right)$ as that is the characteristic feature of anionic polymerization reactions. Using the proton-transfermediated polymerization of $\mathrm{EtG}$, the degree of polymerization $\left(\mathrm{DP}_{\mathrm{n}}\right)$ was mainly determined by the concentration of monomer and that of EtG hydrate, which was directly related to monomer purity and ultimately varied batch-to-batch. Consequently, although PEtGs with high molar masses were obtained, the method suffered from a lack of control over the $\mathrm{DP}_{\mathrm{n}}$ and the nature of the initiating species. The Moore group reported the sole attempt for the polymerization of EtG using a strong base as an initiator. ${ }^{50}$ First, they thoroughly studied the mechanism of cationic polymerization of EtG to prepare interesting cyclic and lariat-shaped PEtGs which were not self- 
immolative due to the lack of stimuli-responsive end-caps (Scheme 1b). Then, they used $n$-BuLi as an initiator, targeting a PEtG with $\mathrm{DP}_{\mathrm{n}}=20$. However, the resulting PEtGs had two end-caps per polymer chain, as indicated by ${ }^{1} \mathrm{H}$ NMR spectroscopy. Presumably, $n$-BuLi was not the actual initiator due to its quenching by EtG hydrate and the polymerization was not controlled.

(a)

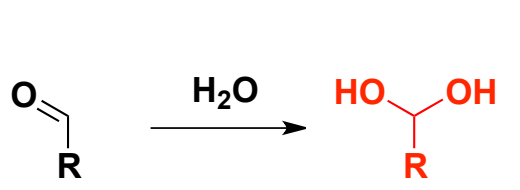

1) 2n monomers

2) Proton-shuttle

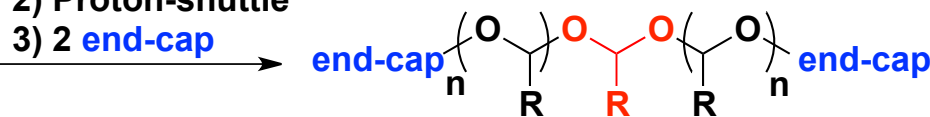

EtG

Hydrate

(b)

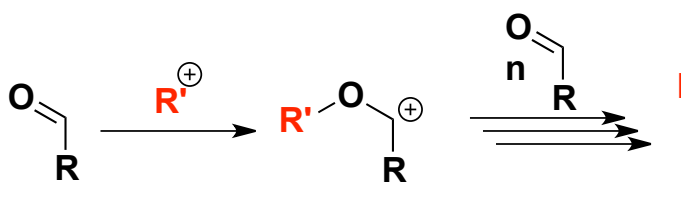<smiles>[R]OC1OC([R])OC([R])([2H])OC1=O</smiles><smiles>[R]C1OC2([R])OC([R])OC([R])(O1)O2</smiles>

(c)

This work:

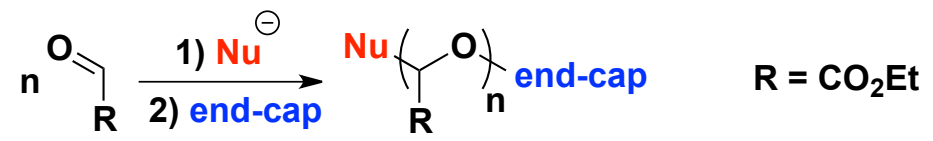

Scheme 1. (a) Proton-transfer-mediated, (b) cationic, and (c) anionic polymerization of PEtG.

For the work described herein, we hypothesized that if we could improve the quality of EtG by lowering the concentration of hydrates to the point that there would not be enough hydrates to significantly quench the introduced alkyllithium reagents, the synthesis of PEtGs with predictable $\mathrm{DP}_{\mathrm{n}}$ could be feasible through anionic polymerization. This requires an extremely pure EtG, but to the best of our knowledge a well-documented method for that has not been reported. This gap prompted us to develop a rigorous and reproducible method for the purification of EtG before our anionic polymerization studies. We also explored the anionic polymerization of EtG using different alkyllithium reagents and alkoxides as initiators and explored the effects of temperature, polymerization time, and monomer to initiator ratios. 


\section{EXPERIMENTAL SECTION}

General procedures and materials. All reactions and manipulations were carried out under a nitrogen atmosphere using standard glovebox or Schlenk techniques. Specifically, the glassware were rapidly set up while they were extremely hot $\left(c a .165^{\circ} \mathrm{C}\right)$. Instantly after that, they were pumped for 5-10 minutes (depending on the size of the flask) using an Edwards RV5 rotary vane pump and then filled with dried $\mathrm{N}_{2}$ before repeating this procedure two more times. EtG solution (ca. $50 \%$ in toluene) was obtained from Alfa Aesar and purified as described below. $\mathrm{CaH}_{2}, \mathrm{P}_{2} \mathrm{O}_{5}$, benzyl chloroformate, propargyl alcohol, PhLi solution (1.9 M in dibutyl ether), $t$-BuLi solution (1.7 $\mathrm{M}$ in pentane), and $n$-BuLi solution (2.5 $\mathrm{M}$ in hexanes) were obtained from Sigma-Aldrich and used as received. Poly(ethylene glycol) (average $\mathrm{M}_{\mathrm{n}}=600 \mathrm{~g} / \mathrm{mol}$ ) was purchased from SigmaAldrich and vacuum-dried in the presence of $\mathrm{P}_{2} \mathrm{O}_{5}$ at $50{ }^{\circ} \mathrm{C}$ for $16 \mathrm{~h}$. Toluene was obtained from Caledon Laboratories and refluxed/distilled over sodium using benzophenone as an indicator. $\mathrm{NEt}_{3}$ was purchased from EMD Millipore corporation, stored over $\mathrm{CaH}_{2}$ for $16 \mathrm{~h}$, and then refluxed for $3 \mathrm{~h}$ before it was distilled prior to use. $\mathrm{CH}_{2} \mathrm{Cl}_{2}$ was obtained from Caledon Laboratories, stored over $\mathrm{CaH}_{2}$ for $16 \mathrm{~h}$, and then refluxed for $3 \mathrm{~h}$ before it was thermally distilled prior to use.

NMR Spectroscopy. ${ }^{1} \mathrm{H},{ }^{13} \mathrm{C}\left\{{ }^{1} \mathrm{H}\right\}$, and ${ }^{31} \mathrm{P}$ NMR spectra were recorded on a $600 \mathrm{MHz}$ Varian INOVA 600 instrument or $400 \mathrm{MHz}$ Bruker AvIII HD 400 instrument. ${ }^{1} \mathrm{H}$ NMR spectra were referenced to residual $\mathrm{CHCl}_{3}(7.27 \mathrm{ppm})$ or $\mathrm{C}_{5} \mathrm{D}_{5} \mathrm{CD}_{2} \mathrm{H}(2.09 \mathrm{ppm})$ and ${ }^{13} \mathrm{C}\left\{{ }^{1} \mathrm{H}\right\}$ NMR spectra were referenced to $\mathrm{CDCl}_{3}(77.0 \mathrm{ppm})$. Ampules of deuterated toluene were purchased from SigmaAldrich and used as received. Deuterated chloroform was obtained from Sigma-Aldrich and stirred over $\mathrm{CaH}_{2}$ for $16 \mathrm{~h}$ before it was collected under vacuum and stored under a nitrogen atmosphere over $4 \AA$ A molecular sieves. 
Variable-temperature ${ }^{1} \boldsymbol{H}$ NMR spectroscopy. Using a glovebox and inside a dry NMR tube, freshly distilled EtG $(0.20 \mathrm{~mL})$ was dissolved in deuterated toluene $(0.80 \mathrm{~mL})$. The NMR tube was charged with $n$-butyllithium solution ( $4 \mu \mathrm{L}, 2.5 \mathrm{M}$ in hexanes), sealed, and vigorously mixed using a vortex mixer. Inside the spectrometer, the NMR sample was gradually cooled to $-60{ }^{\circ} \mathrm{C}$ and kept for another $5 \mathrm{~min}$ before locking/shimming (in 3-5 min) and recording the spectrum. For higher temperatures, the sample was gradually heated to the targeted temperature, over $c a .5 \mathrm{~min}$, and kept at that temperature for extra 5 min before locking, shimming, and finally data collection. The NMR spectra were recorded in $c a .15$ min intervals.

Size exclusion chromatography (SEC). Chromatography-grade tetrahydrofuran (THF) was purchased from Caledon Laboratories and used as received. SEC experiments were conducted using THF solutions at concentrations of $c a .5 \mathrm{mg} / \mathrm{mL}$ using a Viscotek GPCmax VE 2001 SEC instrument equipped with an Agilent PolyPore guard column (PL1113-1500) and two sequential Agilent PolyPore SEC columns packed with porous poly(styrene-co-divinylbenzene) particles (MW range: 2002,000,000 g/mol; PL1113-6500) regulated at a temperature of $30^{\circ} \mathrm{C}$. Signal responses were measured using a Viscotek VE 3580 RI detector, and molar masses were determined by comparison poly(methyl methacrylate) (PMMA) standards purchased from Viscotek.

Thermal analysis. Thermogravimetric analyses (TGA) were performed using a TA Instruments Q50 TGA. Samples were placed in a platinum pan and heated at a rate of $10{ }^{\circ} \mathrm{C} / \mathrm{min}$ from 25 to $1000{ }^{\circ} \mathrm{C}$ under a flow of nitrogen $(60 \mathrm{~mL} / \mathrm{min})$. Differential scanning calorimetry (DSC) thermograms were acquired using a TA Instruments DSC Q20 instrument. The polymer samples were placed in an aluminum Tzero pan and heated from room temperature to $150^{\circ} \mathrm{C}$ at $10^{\circ} \mathrm{C} / \mathrm{min}$ under a flow of nitrogen (50 $\mathrm{mL} / \mathrm{min}$ ) and cooled to $-50^{\circ} \mathrm{C}$ at $10^{\circ} \mathrm{C} / \mathrm{min}$, before they underwent two additional heating/cooling cycles. 
Purification of ethyl glyoxylate. A commercial solution of ethyl glyoxylate in toluene $(200 \mathrm{~mL}$, ca. $50 \%$ in toluene) was transferred into a $250 \mathrm{~mL}$ Schlenk flask equipped with a stir bar. The flask was placed inside a water bath (at $25^{\circ} \mathrm{C}$ ) and attached to a cold trap at $-196{ }^{\circ} \mathrm{C}$. The solution was then concentrated under vacuum until about $100 \mathrm{~mL}$ of high-viscosity colorless liquid was left. Next, the flask was detached from the trap, charged with $\mathrm{P}_{2} \mathrm{O}_{5}(8.5 \mathrm{~g})$, and attached to a short-path distillation head equipped with a cow-type distillation receiver (Figure S1a). The distillation head was wrapped with glass wool and a layer of aluminum foil before the main flask was placed inside a silicon oil bath (Figures S1b-c). The distillation setup and hotplate were covered with another layer of aluminum foil, then heated at $110^{\circ} \mathrm{C}$ for $10 \mathrm{~min}$. Next, the temperature of the oil bath was increased to $165^{\circ} \mathrm{C}$ (Figure S1d). The first fraction (about $5 \mathrm{~mL}$ ) was collected in the first flask and contained toluene. The collection flask was then switched to the second Schlenk flask with only its bottom cooled at $-78^{\circ} \mathrm{C}$. Note that the contamination of EtG with silicon grease drastically lowers its quality and cooling the greased areas of the collection flask results in the condensation of EtG on those surfaces. The thermal distillation was continued until the condensation drastically slowed down ( $c a .20-30 \mathrm{~min}$ ) and a low-viscosity pale-yellow liquid was collected ( $c a .65 \mathrm{~mL}$ ). The collection flask was then detached from the distillation receiver, charged with $\mathrm{P}_{2} \mathrm{O}_{5}(2.0 \mathrm{~g})$, and equipped with another short-path distillation head which was directly attached to a collection Schlenk flask. Like the first distillation, the distillation head was insulated using glass wool/aluminum foil and the main flask was heated at $165^{\circ} \mathrm{C}$ until the condensation stopped $(c a$. $20 \mathrm{~min}$ ). The final product was gathered as a pale-yellow and low-viscosity liquid (ca. $45 \mathrm{~mL}$, Figure S1f). ${ }^{1} \mathrm{H}$ NMR (600 MHz, $\left.\mathrm{CDCl}_{3}\right): \delta 9.28(\mathrm{~s}, 1 \mathrm{H}, \mathrm{CHO}), 4.26\left(\mathrm{q}, \mathrm{J}=7 \mathrm{~Hz}, 2 \mathrm{H}, \mathrm{CH}_{2}\right), 1.28(\mathrm{t}, \mathrm{J}$ $\left.=7 \mathrm{~Hz}, 3 \mathrm{H}, \mathrm{CH}_{3}\right)$. 
NEt 3 -mediated polymerization of EtG. In a Schlenk flask, freshly distilled $\mathrm{CH}_{2} \mathrm{Cl}_{2}(5.0 \mathrm{~mL})$ and EtG $(5.0 \mathrm{~mL}, 50 \mathrm{mmol})$ were combined at room temperature and vigorously stirred for $3 \mathrm{~min}$ before the addition of $\mathrm{NEt}_{3}(5 \mu \mathrm{L}, 0.04 \mathrm{mmol})$. The resulting solution was stirred for another 10

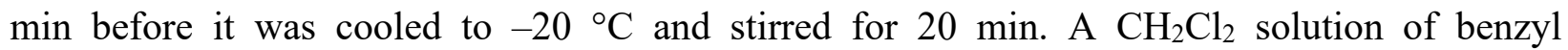
chloroformate $(5.5 \mathrm{~mL}, 1 / 10 \mathrm{v} / \mathrm{v}, 4 \mathrm{mmol})$ was instantly added and then additional $\mathrm{NEt}_{3}(0.5 \mathrm{~mL}$, $4 \mathrm{mmol}$ ) was added. The resulting mixture was stirred for $3 \mathrm{~h}$ at $-20{ }^{\circ} \mathrm{C}$ before it was allowed to gradually reach $20^{\circ} \mathrm{C}$ over $16 \mathrm{~h}$. Then, the polymerization mixture was precipitated into methanol $(200 \mathrm{~mL})$ before decanting the solvent and drying of the resulting residue under vacuum. Yield $=$

$3.25 \mathrm{~g}, 65 \%$. The ${ }^{1} \mathrm{H}$ NMR spectrum was consistent with that previously reported (Figure S5). ${ }^{47}$ SEC: $M_{n}=75,500 \mathrm{~g} / \mathrm{mol}, M_{w}=102,750 \mathrm{~g} / \mathrm{mol}, \emptyset=1.36, \mathrm{DP}_{\mathrm{n}}=740$.

\section{Anionic polymerization of PEtGs}

Representative procedure for the alkyllithium-initiated polymerization of EtG. In a Schlenk flask, freshly distilled toluene (4 volumes) and a $n$-BuLi solution were combined at room temperature and vigorously stirred for 3 min. The flask was then instantly charged with freshly distilled EtG (1 volume) and stirred for another $10 \mathrm{~min}$ before cooling the solution to $-20{ }^{\circ} \mathrm{C}$ and stirring at that temperature for $20 \mathrm{~min}$. Then, freshly distilled $\mathrm{NEt}_{3}(0.1$ volume $)$ was instantly added and the resulting solution was stirred for $10 \mathrm{~min}$ before the addition of benzyl chloroformate ( 0.1 volume). The resulting mixture was stirred for another $3 \mathrm{~h}$ at $-20^{\circ} \mathrm{C}$, then it was allowed to gradually reach $20{ }^{\circ} \mathrm{C}$ over $16 \mathrm{~h}$. Concentration of the polymerization mixture, in vacuo at $45^{\circ} \mathrm{C}$, gave crude residues containing $\mathrm{PEtG}, \mathrm{HN}^{+} \mathrm{Et}_{3} \mathrm{Cl}$, residual EtG, benzyl chloroformate, and $\mathrm{NEt}_{3}$. The mixtures were purified according to their average molar mass. PEtGs with $\mathrm{M}_{\mathrm{n}} \geq 20,000 \mathrm{~g} / \mathrm{mol}$ were dissolved in a minimum amount of $\mathrm{CH}_{2} \mathrm{Cl}_{2}$ (2 volumes) and precipitated into methanol (40 volumes). The solvent was decanted and the resulting residue was dried under vacuum. This 
afforded PEtGs in 70-95\% yield. PEtGs with 20,000 $>\mathrm{M}_{\mathrm{n}}>10,000 \mathrm{~g} / \mathrm{mol}$ were dissolved in a minimum amount of $\mathrm{CH}_{2} \mathrm{Cl}_{2}$ (1.5 volumes) and precipitated into a solvent mixture (methanol/water $9 / 1 ; 40$ volume). The flasks were then sealed and transferred into a $-20{ }^{\circ} \mathrm{C}$ freezer where they were kept for $16 \mathrm{~h}$ before decanting the solvent and vacuum-drying of the resulting residues. These procedures afforded PEtGs in $60-80 \%$ yield. PEtGs with $\mathrm{M}_{\mathrm{n}}<10,000 \mathrm{~g} / \mathrm{mol}$ were dissolved in $\mathrm{CH}_{2} \mathrm{Cl}_{2}$ (1.5 volume) and precipitated into a solvent mixture (methanol/water 4/1; 50 volumes). Then, the flasks were sealed and transferred into a $-20{ }^{\circ} \mathrm{C}$ freezer where they were kept for $16 \mathrm{~h}$ before decanting the solvent and vacuum-drying the resulting residues. This latter procedure afforded PEtGs in 50-70\% yield. Note: to keep the polymerization results comparable

Variation of polymerization time (Polymers 1-5). From the same batch of monomer, a series of five polymerizations were performed following the representative procedure with some changes. EtG (5.0 mL, $50 \mathrm{mmol}, 100$ equiv.) was added to a $n$-BuLi solution ( $0.5 \mathrm{mmol}$ in $20.0 \mathrm{~mL}$ toluene) at $-20^{\circ} \mathrm{C}$. After $5 \mathrm{~min}$ (for Polymer 1), $10 \mathrm{~min}$ (for Polymer 2), $20 \mathrm{~min}$ (for Polymer 3), $30 \mathrm{~min}$ (for Polymer 4), and $60 \mathrm{~min}$ (for Polymer 5), $\mathrm{NEt}_{3}(0.5 \mathrm{~mL}, 4 \mathrm{mmol}$ ) and benzyl chloroformate (0.5 mL, $4 \mathrm{mmol})$ were added simultaneously. See Table 1 for the SEC results of the unpurified polymers.

Note: Polymers 6-9 were prepared from the same batch of monomer.

Synthesis of Polymer 6. From EtG (5.0 mL, 50 mmol, 200 equiv.), toluene (20.0 mL), $n$-BuLi solution $(100 \mu \mathrm{L}, 2.5 \mathrm{M}$ in hexanes, $0.25 \mathrm{mmol}), \mathrm{NEt}_{3}(0.5 \mathrm{~mL}, 4 \mathrm{mmol})$, and benzyl chloroformate (0.5 mL, $4 \mathrm{mmol})$. EtG was added to the $n$-BuLi/toluene solution at $-78{ }^{\circ} \mathrm{C}$. See Table 1 for the SEC results of the unpurified polymer. 
Synthesis of Polymer 7. From EtG (5.0 mL, $50 \mathrm{mmol}, 200$ equiv.), toluene (20.0 mL), $n$-BuLi solution $(100 \mu \mathrm{L}, 2.5 \mathrm{M}$ in hexanes, $0.25 \mathrm{mmol}), \mathrm{NEt}_{3}(0.5 \mathrm{~mL}, 4 \mathrm{mmol})$, benzyl chloroformate $(0.5 \mathrm{~mL}, 4 \mathrm{mmol})$, and following the optimized procedure. Yield $=3.5 \mathrm{~g}, 70 \% .{ }^{1} \mathrm{H} \mathrm{NMR}(600 \mathrm{MHz}$, $\left.\mathrm{CDCl}_{3}\right): \delta 7.43-7.30(\mathrm{~m}, 9.8 \mathrm{H}), 5.80-5.47(\mathrm{~m}, 278 \mathrm{H}), 5.19(\mathrm{~s}, 3.4 \mathrm{H}), 4.36-4.08(\mathrm{~m}, 568 \mathrm{H}), 1.43-1.20$ (m, 855H), 0.95-0.78 (m, 3.0H). ${ }^{13} \mathrm{C}\left\{{ }^{1} \mathrm{H}\right\} \mathrm{NMR}\left(101 \mathrm{MHz}, \mathrm{CDCl}_{3}\right): \delta 166.3-165.0,128.8-128.1,94.2-$ 90.5, 62.0, 13.8. See Table 1 and S1 for the SEC results.

Synthesis of Polymer 8. From EtG (5.0 mL, $50 \mathrm{mmol}, 200$ equiv.), toluene (20.0 mL), PhLi solution $\left(131 \mu \mathrm{L}, 1.9 \mathrm{M}\right.$ in dibutyl ether, $0.25 \mathrm{mmol}^{2}, \mathrm{NEt}_{3}(0.5 \mathrm{~mL}, 4 \mathrm{mmol})$, benzyl chloroformate $(0.5 \mathrm{~mL}, 4 \mathrm{mmol})$, and following the optimized procedure. See Table 1 for the SEC results of the unpurified polymer.

Synthesis of Polymer 9. From EtG (5.0 mL, $50 \mathrm{mmol}, 200$ equiv.), toluene (20.0 mL), $t$-BuLi solution $(147 \mu \mathrm{L}, 1.7 \mathrm{M}$ in pentane, $0.25 \mathrm{mmol}), \mathrm{NEt}_{3}(0.5 \mathrm{~mL}, 4 \mathrm{mmol})$, benzyl chloroformate ( $0.5 \mathrm{~mL}, 4 \mathrm{mmol})$, and following the optimized procedure. See Table 1 for the SEC results of the unpurified polymer.

Length-control experiments using n-BuLi (Polymers 10-14). From the same batch of monomer, a series of five polymerizations were performed following the optimized procedure without any changes. The feed molar ratios (EtG/n-BuLi) were 50, 100, 200, 400, and 600. From EtG (5.0 mL, $50 \mathrm{mmol}$ ), toluene (20.0 mL), $n$-BuLi solution (2.5 M in hexanes, 400, 200, 100, 50, and $33 \mu \mathrm{L}$ ), $\mathrm{NEt}_{3}(0.5 \mathrm{~mL}, 4 \mathrm{mmol})$, and benzyl chloroformate $(0.5 \mathrm{~mL}, 4 \mathrm{mmol})$. See Table 1 and $\mathrm{S} 1$ for the SEC results.

Note: Polymers 15-17 were prepared from the same batch of monomer. 


\section{Synthesis of Polymer 15 and representative procedure for the alkoxide-initiated}

polymerization of EtG. In a Schlenk flask, propargyl alcohol (29 $\mu \mathrm{L}, 0.50 \mathrm{mmol}, 1.0$ equiv.) was combined with a $n$-BuLi solution $(200 \mu \mathrm{L}, 2.5 \mathrm{M}$ in hexanes, $0.50 \mathrm{mmol}, 1.0$ equiv.) in freshly distilled toluene $(20.0 \mathrm{~mL})$. After stirring for $10 \mathrm{~min}$ at $20^{\circ} \mathrm{C}$, the flask was instantly charged with freshly distilled EtG (5.0 mL, $50 \mathrm{mmol}, 100$ equiv.) and stirred for another $20 \mathrm{~min}$ before the solution was cooled to $-20{ }^{\circ} \mathrm{C}$ and stirred at that temperature for $20 \mathrm{~min}$. Then, freshly distilled $\mathrm{NEt}_{3}(0.5 \mathrm{~mL}, 4 \mathrm{mmol})$ was instantly added and the resulting solution was stirred for 10 min before the addition of benzyl chloroformate $(0.5 \mathrm{~mL}, 4 \mathrm{mmol})$. The resulting mixture was stirred for another $3 \mathrm{~h}$ at $-20{ }^{\circ} \mathrm{C}$, then it was allowed to gradually reach $20{ }^{\circ} \mathrm{C}$ over $16 \mathrm{~h}$. The purification was conducted following our optimized method. Yield $=3.0 \mathrm{~g}, 60 \% .{ }^{1} \mathrm{H} \mathrm{NMR}\left(600 \mathrm{MHz}, \mathrm{CDCl}_{3}\right): \delta$ 7.43-7.30 (m, 6.8H), 5.80-5.47 (m, 103H), $5.20(\mathrm{~s}, 2.6 \mathrm{H}), 4.36-4.08(\mathrm{~m}, 204 \mathrm{H}), 2.55-2.45(\mathrm{~m}, 1.2 \mathrm{H})$, $1.43-1.20(\mathrm{~m}, 308 \mathrm{H}), 0.95-0.78(\mathrm{~m}, 3.0 \mathrm{H})$. See Table 1 and $\mathrm{S} 1$ for the SEC results.

Synthesis of Polymer 16. From PEG diol (150 mg, $0.500 \mathrm{mmol}$ of OH, 1.0 equiv.), $n$-BuLi solution (2.5 $\mathrm{M}$ in hexanes, $200 \mu \mathrm{L}, 0.50 \mathrm{mmol}, 1.0$ equiv.), toluene $(20.0 \mathrm{~mL})$, EtG $(5.0 \mathrm{~mL}, 50 \mathrm{mmol}$, 100 equiv.), $\mathrm{NEt}_{3}(0.5 \mathrm{~mL}, 4 \mathrm{mmol})$, and benzyl chloroformate $(0.5 \mathrm{~mL}, 4 \mathrm{mmol})$. The time of lithiation step was increased to $1 \mathrm{~h}$ and the reaction time between EtG/dialkoxide was increased to $2 \mathrm{~h}$. The purification was conducted following our optimized method. Yield $=3.5 \mathrm{~g}, 70 \%$. ${ }^{1} \mathrm{H}$ NMR (600 MHz, $\left.\mathrm{CDCl}_{3}\right): \delta 7.43-7.30(\mathrm{~m}, 17.4 \mathrm{H}), 5.80-5.47(\mathrm{~m}, 248 \mathrm{H}), 5.20(\mathrm{~s}, 5.8 \mathrm{H}), 4.36-4.08(\mathrm{~m}, 517 \mathrm{H})$, 3.95-3.55 (m, 52H), 1.43-1.20 (m, 771H). See Table 1 and $\mathrm{S} 1$ for the SEC results.

Synthesis of Polymer 17. Following the above procedure and from PEG diol (37.5 mg, 0.125 mmol of $\mathrm{OH}, 1.0$ equiv.), $n$-BuLi solution (2.5 $\mathrm{M}$ in hexanes, $50 \mu \mathrm{L}, 0.13 \mathrm{mmol}, 1.0$ equiv.), toluene (20.0 mL), EtG (5.0 mL, $50 \mathrm{mmol}, 400$ equiv.), $\mathrm{NEt}_{3}(0.5 \mathrm{~mL}, 4 \mathrm{mmol})$, and benzyl chloroformate $(0.5 \mathrm{~mL}, 4 \mathrm{mmol})$. Yield $=3.5 \mathrm{~g}, 70 \% .{ }^{1} \mathrm{H} \mathrm{NMR}\left(600 \mathrm{MHz}, \mathrm{CDCl}_{3}\right): \delta 7.43-7.30(\mathrm{~m}$, 
$18.8 \mathrm{H}), 5.80-5.47(\mathrm{~m}, 667 \mathrm{H}), 5.20(\mathrm{~s}, 5.2 \mathrm{H}), 4.36-4.08(\mathrm{~m}, 1357 \mathrm{H}), 3.95-3.55(\mathrm{~m}, 52 \mathrm{H}), 1.43-1.20$ (m, 2039H). See Table 1 and S1 for the SEC results.

\section{RESULTS AND DISCUSSION}

Monomer purification. The optimized purification procedure included three steps: toluene removal and two thermal distillations using $\mathrm{P}_{2} \mathrm{O}_{5}$ as a drying agent. At $20{ }^{\circ} \mathrm{C}$, toluene was first removed from a commercial toluene solution of $\operatorname{EtG}(c a .50 \% \mathrm{v} / \mathrm{v})$ in vacuo. Although the boiling point of EtG and toluene are similar, the distilled fraction mostly contained toluene because in toluene solution EtG mostly exists in oligomeric form which does not depolymerize and distill under these conditions. In addition, the concentration process further shifts the equilibrium toward oligomers (Scheme 2). Thus, the first step yielded a colorless and viscous residue that mainly consisted of oligomeric PEtGs (Figure S2).

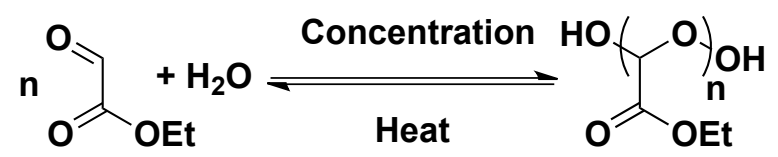

Scheme 2. Effect of temperature and concentration on EtG/PEtG equilibrium.

To estimate the required amount of drying agent for the first thermal distillation, the number of oligomer chains per gram of the residue was calculated by estimating the $\mathrm{M}_{\mathrm{n}}$ for the oligomers using SEC. In a typical batch, oligomers with $\mathrm{DP}_{\mathrm{n}} \sim 6$ were attained. Although we had previously used $\mathrm{P}_{2} \mathrm{O}_{5}$ as a drying agent, $\mathrm{CaH}_{2}$ was also investigated in this work. $\mathrm{CaH}_{2}$ was relatively slow in cracking the oligomers and yielded low quality monomers contaminated with unknown impurities, even when a batch of crude monomer was refluxed at $165^{\circ} \mathrm{C}$ for $3 \mathrm{~h}$ before 
the thermal distillation. Longer refluxing times and higher temperatures resulted in degradation of the monomer.

In contrast, $\mathrm{P}_{2} \mathrm{O}_{5}$ afforded pure monomer when the crude mixture was heated at $165^{\circ} \mathrm{C}$. At higher temperatures, $\mathrm{H}_{3} \mathrm{PO}_{4}$ was collected with $\mathrm{EtG}$ as it is produced due to the reaction of $\mathrm{P}_{2} \mathrm{O}_{5}$ with water and boils at $c a .155^{\circ} \mathrm{C}$. For further analysis, a sample of EtG which was collected at $185{ }^{\circ} \mathrm{C}$ was characterized by ${ }^{1} \mathrm{H}$ and ${ }^{31} \mathrm{P}\left\{{ }^{1} \mathrm{H}\right\}$ NMR spectroscopy. $\mathrm{H}_{3} \mathrm{PO}_{4}$ gave rise to a single resonance at $-1.2 \mathrm{ppm}$ in the ${ }^{31} \mathrm{P}\left\{{ }^{1} \mathrm{H}\right\}$ NMR spectrum (Figure S3). In addition, the comparison of ${ }^{1} \mathrm{H}$ NMR spectra recorded for pure EtG and the contaminated fraction showed that $\mathrm{H}_{3} \mathrm{PO}_{4}$ lowers the quality of EtG by the production of some oligomers (Figure S4). It is noteworthy that the excessive use of $\mathrm{P}_{2} \mathrm{O}_{5}$ lowers the yield and insufficient use of $\mathrm{P}_{2} \mathrm{O}_{5}$ results in the incomplete conversion of oligomers to low-quality EtG. Moreover, short Vigreux columns were utilized to gain a better control over the separation of $\mathrm{EtG}$ from $\mathrm{H}_{3} \mathrm{PO}_{4}$. However, in our experience, distilling at $165^{\circ} \mathrm{C}$ while the distillation setup is carefully insulated and collecting EtG in the first $20-30$ min after reaching $165{ }^{\circ} \mathrm{C}$ can successfully prevent the collection of $\mathrm{H}_{3} \mathrm{PO}_{4}$.

We also explored the vacuum distillation of EtG at lower temperatures but found that this resulted in the condensation and polymerization of $\mathrm{EtG}$ on the greased areas of glass joints. Thus, the optimized procedure involved an initial distillation of EtG over $\sim 2$ equiv. of $\mathrm{P}_{2} \mathrm{O}_{5}$ per oligomer at $165{ }^{\circ} \mathrm{C}$ under ambient pressure, followed by a second distillation at the same pressure and temperature (Figure S1). This three-step method was conducted several times and all batches afforded high-quality EtGs.

Synthesis and characterization of PEtGs. The polymerization behavior of distilled EtG was studied by conducting a series of polymerization experiments using $\mathrm{NEt}_{3}$ and various anionic initiators. Although the benzyl carbonate group is a non-responsive end-cap, benzyl chloroformate 
was employed as an end-capping agent as it is efficient and inexpensive. Based on our previous work, it should be straightforward to apply the developed methods to other chloroformates leading to stimuli-responsive PEtGs. ${ }^{47,48}$

Proton-transfer-mediated polymerization. First, to examine the quality of distilled monomer and establish a benchmark based on our previous method, ${ }^{47}$ a $\mathrm{NEt}_{3}$-mediated polymerization was performed. At $-20^{\circ} \mathrm{C}$, a catalytic amount of $\mathrm{NEt}_{3}$ was added to a $\mathrm{CH}_{2} \mathrm{Cl}_{2}$ solution of $\mathrm{EtG}$, and after 30 min a solution of benzyl chloroformate and an additional amount of $\mathrm{NEt}_{3}$ were added to endcap PEtG. After $3 \mathrm{~h}$ of stirring at $c a .-20{ }^{\circ} \mathrm{C}$, the polymerization mixture was warmed to $20^{\circ} \mathrm{C}$ over a period of $\sim 16 \mathrm{~h}$. The resulting polymer was purified by precipitation into methanol. Vacuum-drying of the resulting precipitate yielded PEtG in 65\% yield. Consistent with previous reports, ${ }^{47}$ in the ${ }^{1} \mathrm{H}$ NMR spectrum, protons of repeating units gave rise to broad peaks associated with $\mathrm{CH}, \mathrm{CH}_{2}$, and $\mathrm{CH}_{3}$ at $\mathrm{ca} .5 .5,4.2$, and $1.2 \mathrm{ppm}$, respectively, in addition to phenyl and benzylic protons of the end-groups at $c a .7 .3$ and $5.2 \mathrm{ppm}$, respectively (Figure S5). Due to the very low intensity of the end-cap signals relative to those of the repeating units, an accurate ${ }^{1} \mathrm{H}$ NMR endgroup analysis could not be performed to calculate the molar mass of this PEtG batch. However, based on ${ }^{1} \mathrm{H}$ NMR end-group analysis for shorter PEtGs, we have found that the data obtained by SEC in THF using PMMA standards provides a good estimate of the PEtG molar mass. Thus, SEC was the technique of choice for comparing the molar masses of the PEtGs with a wide range of $\mathrm{DP}_{\mathrm{n}}$ values included in this study. Based on SEC, the purified PEtG obtained by $\mathrm{NEt}_{3}$-mediated polymerization had an $\mathrm{M}_{\mathrm{n}}$ of $75,500 \mathrm{~g} / \mathrm{mol}, \mathrm{M}_{\mathrm{w}}=102,750 \mathrm{~g} / \mathrm{mol}, \nexists=1.36$, and $\mathrm{DP}_{\mathrm{n}}=740$. The ability to obtain a high molar mass PEtG confirmed the high quality of our distilled monomer.

Anionic polymerization of EtG. The reaction temperature and time were optimized. In addition, the performance of different alkyllithium reagents and alkoxides in controlling the polymerization 
was studied (Scheme 3) based on the SEC results for the resulting unpurified polymers as this would provide the most accurate depiction of the polymers produced during the polymerization rather than those that had been fractionated to some extent by purification.
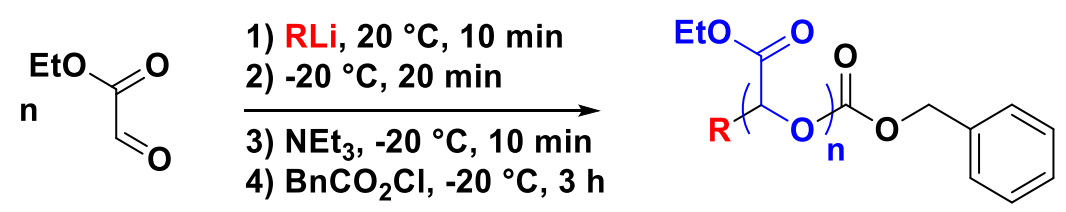

Scheme 3. Anionic polymerization of EtG using alkyllithium reagents as initiators.

Polymerization temperature. Polyacetals like PEtG are typically polymerized at low temperatures due to their low ceiling temperatures $\left(T_{c}\right) .{ }^{51}$ To optimize the propagation/end-capping temperature and also determine the $T_{c}$, a NMR tube containing a solution of EtG in deuterated toluene (20\% $\mathrm{v} / \mathrm{v}$ ) was charged with a $n$-BuLi solution, and after being sealed under $\mathrm{N}_{2}$ it was characterized using variable-temperature (VT) ${ }^{1} \mathrm{H}$ NMR spectroscopy (Figure 1a). The conversion of EtG to PEtG was monitored by the comparison of the backbone peak of PEtG ( $c a .5 .5 \mathrm{ppm}$ ) with the aldehyde peak of EtG (ca. $8.9 \mathrm{ppm})$. At $-60^{\circ} \mathrm{C}$, PEtG had very broad resonances which were overlapped with very low intensity peaks of residual EtG. At $-20{ }^{\circ} \mathrm{C}$, polymer peaks were much better resolved and EtG/PEtG ratio was calculated to be 2/98. By increasing the temperature to 20 ${ }^{\circ} \mathrm{C}$, a considerable amount of PEtG was converted to EtG. At $80{ }^{\circ} \mathrm{C}$, nearly complete conversion of PEtG to EtG was observed, i.e., 93\% EtG. 
(a)

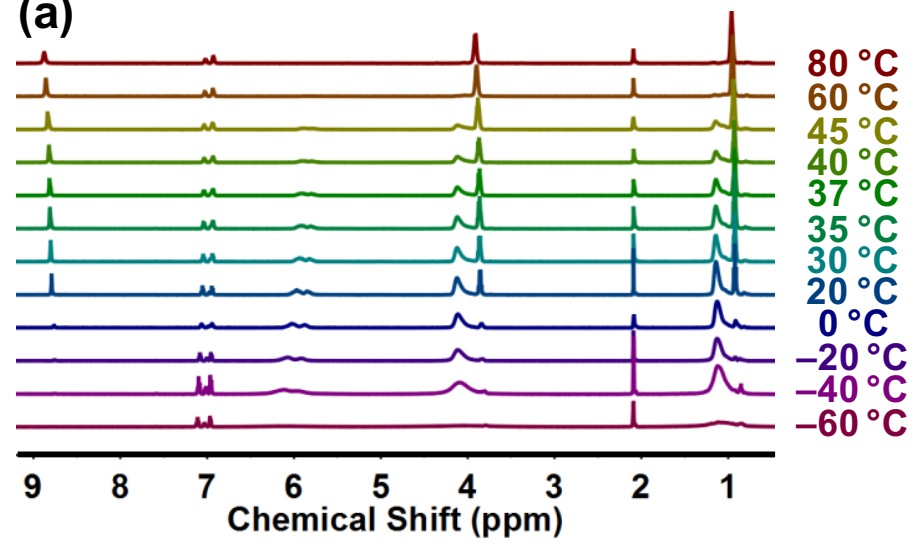

(b) $0.0032 \quad 0.0036 \quad 0.004 \quad 0.0044$

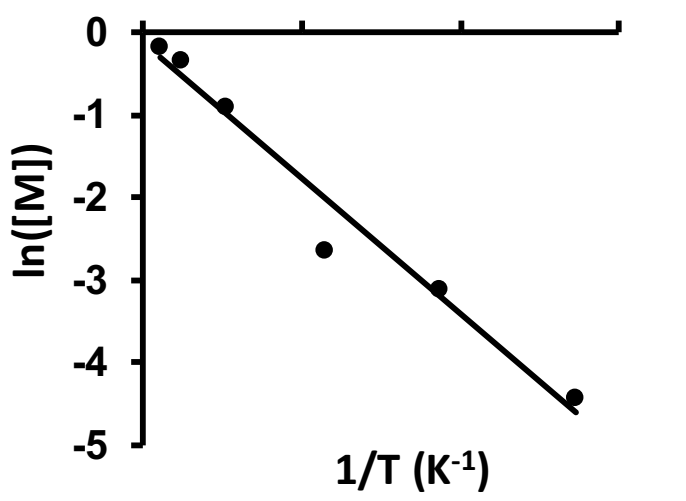

Figure 1. (a) In situ ${ }^{1} \mathrm{H}$ NMR spectra for the anionic polymerization of $\mathrm{EtG}$ in deuterated toluene and (b) natural $\log$ of monomer concentration $v s$. inverse temperature for data points recorded for the temperature range of $-40{ }^{\circ} \mathrm{C}$ to $35^{\circ} \mathrm{C}$.

$T_{c}$ calculations were performed following Dainton's method ${ }^{52}$ and using the equilibrium concentration of EtG at different temperatures in deuterated toluene (Table S1). In equations (1) and (2), $[M]$ is the EtG concentration; $[M]_{0}$ is the initial EtG concentration, i.e., $1.96 \mathrm{M} ; R$ is the ideal gas constant; $T$ is the temperature in Kelvin; $\Delta S^{\circ}$ is the standard change in the entropy of polymerization; and $\Delta H^{\circ}$ is the standard change in the enthalpy of polymerization.

$$
\begin{gathered}
\ln [M]=\left(\frac{\Delta H^{\circ}}{R}\right) \times \frac{1}{T}+\left(-\frac{\Delta S^{\circ}}{R}\right) \\
T_{c}=\frac{\Delta H^{\circ}}{\Delta S^{\circ}+R \times \ln [M]_{0}}
\end{gathered}
$$

A plot of the natural $\log$ of EtG concentration vs. inverse temperature allowed determination of $\Delta H^{\circ}(-34.4 \mathrm{~kJ} / \mathrm{mol})$ and $\Delta S^{\circ}(-109 \mathrm{~J} / \mathrm{mol} \cdot \mathrm{K})$ from the slope and intercept respectively of the linear regression fit (solid line in Figure 1b). Using $\ln [M]_{0}(0.672), \Delta H^{\circ}, \Delta S^{\circ}$, 
and equation (2), a $T_{c}$ of $59{ }^{\circ} \mathrm{C}$ was calculated for our experimental conditions. At $1.0 \mathrm{M}$ concentration of EtG in toluene, our thermodynamic parameters would provide a $T_{c}$ of $42{ }^{\circ} \mathrm{C}$, which is similar to the value of $37^{\circ} \mathrm{C}$ previously reported for PEtG in $\mathrm{CDCl}_{3} .{ }^{44}$ To ensure a high $\mathrm{DP}_{\mathrm{n}}$, it is necessary to be well below $T_{c}$. As at very low temperatures, e.g., $-60^{\circ} \mathrm{C}$, end-capping of PEtG was not trivial and at $-20{ }^{\circ} \mathrm{C}$ a high EtG conversion was still observed, $-20{ }^{\circ} \mathrm{C}$ was selected as the optimized polymerization temperature.

Polymerization time. A series of five anionic polymerizations with the same feed molar ratios, i.e., EtG/n-BuLi $=100$, were performed (Polymers 1-5 in Table 1). For this series of experiments, EtG was added to the toluene solutions of $n$-BuLi at $-20{ }^{\circ} \mathrm{C}$. Then benzyl chloroformate/ $\mathrm{NEt}_{3}$ were added after 5, 10, 20, 30, and 60 min for Polymers 1-5 respectively to end-cap the polymers. After $3 \mathrm{~h}$ of stirring at $c a .-20{ }^{\circ} \mathrm{C}$, the polymerization mixtures were allowed to gradually reach $20^{\circ} \mathrm{C}$ over a period of $16 \mathrm{~h}$. The SEC traces and corresponding $M_{n}$ values for different polymerization times are shown in Figure 2. All five polymerizations gave PEtGs with molar masses close to the targeted values. For Polymer 1, a slightly bimodal distribution was observed probably because end-capping started while the polymer was still growing. Increasing the reaction time above 10 min did not have a meaningful effect on $\mathrm{M}_{\mathrm{n}}$ or $Ð$. This indicates that 10 min was sufficient for the polymerization to reach the maximum conversion. To ensure the reaction was complete, we chose $30 \mathrm{~min}$ for the reaction time.

Table 1. SEC characterization data recorded for unpurified PEtGs prepared under different conditions using different alkyllithium reagents. 


\begin{tabular}{|c|c|c|c|c|c|c|c|c|c|}
\hline Name & Initiator & $\begin{array}{l}\text { Ini. } \\
\text { T }\left({ }^{\circ} \mathrm{C}\right)\end{array}$ & $\begin{array}{l}\text { Polym. } \\
\text { T }\left({ }^{\circ} \mathrm{C}\right)\end{array}$ & $\begin{array}{c}\text { Polym. } \\
\text { Time } \\
\text { (min) }\end{array}$ & $\begin{array}{c}M_{n} \\
(g / m o l)\end{array}$ & $\begin{array}{c}M_{w} \\
(\mathrm{~g} / \mathrm{mol})\end{array}$ & $\boldsymbol{\theta}$ & $\mathbf{D P}_{\mathbf{n}}$ & EtG/Ini. \\
\hline $\begin{array}{c}\text { Polymer } \\
1\end{array}$ & $n$-BuLi & -20 & -20 & 5 & 9,500 & 21,000 & 2.21 & 93 & 100 \\
\hline $\begin{array}{c}\text { Polymer } \\
2\end{array}$ & $n$-BuLi & -20 & -20 & 10 & 8,750 & 19,000 & 2.17 & 86 & 100 \\
\hline $\begin{array}{c}\text { Polymer } \\
3\end{array}$ & $n$-BuLi & -20 & -20 & 20 & 12,750 & 24,000 & 1.88 & 125 & 100 \\
\hline $\begin{array}{c}\text { Polymer } \\
4\end{array}$ & $n$-BuLi & -20 & -20 & 30 & 9,000 & 17,500 & 1.94 & 88 & 100 \\
\hline $\begin{array}{c}\text { Polymer } \\
5\end{array}$ & $n$-BuLi & -20 & -20 & 60 & 8,500 & 15,500 & 1.82 & 83 & 100 \\
\hline $\begin{array}{c}\text { Polymer } \\
6\end{array}$ & $n$-BuLi & -78 & -78 & 30 & 20,000 & 78,250 & 3.91 & 196 & 200 \\
\hline $\begin{array}{c}\text { Polymer } \\
7\end{array}$ & $n$-BuLi & 20 & -20 & 30 & 20,250 & 30,000 & 1.47 & 198 & 200 \\
\hline $\begin{array}{c}\text { Polymer } \\
8\end{array}$ & $\mathrm{PhLi}$ & 20 & -20 & 30 & 21,000 & 32,500 & 1.55 & 206 & 200 \\
\hline
\end{tabular}


$\begin{array}{llllllllll}\text { Polymer } & t \text {-BuLi } & 20 & -20 & 30 & 23,500 & 36,000 & 1.52 & 230 & 200\end{array}$ 9

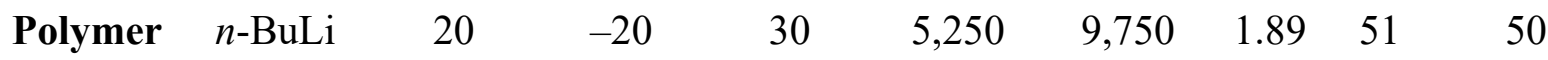
10

$\begin{array}{llllllllll}\text { Polymer } & n \text {-BuLi } & 20 & -20 & 30 & 10,250 & 16,750 & 1.65 & 100 & 100\end{array}$ 11

$\begin{array}{llllllllll}\text { Polymer } & n \text {-BuLi } & 20 & -20 & 30 & 20,500 & 32,500 & 1.59 & 201 & 200\end{array}$ 12

$\begin{array}{llllllllll}\text { Polymer } & n \text {-BuLi } & 20 & -20 & 30 & 31,250 & 46,750 & 1.50 & 306 & 400\end{array}$ 13

$\begin{array}{llllllllll}\text { Polymer } & n-\mathrm{BuLi} & 20 & -20 & 30 & 41,000 & 59,750 & 1.46 & 402 & 600\end{array}$ 14
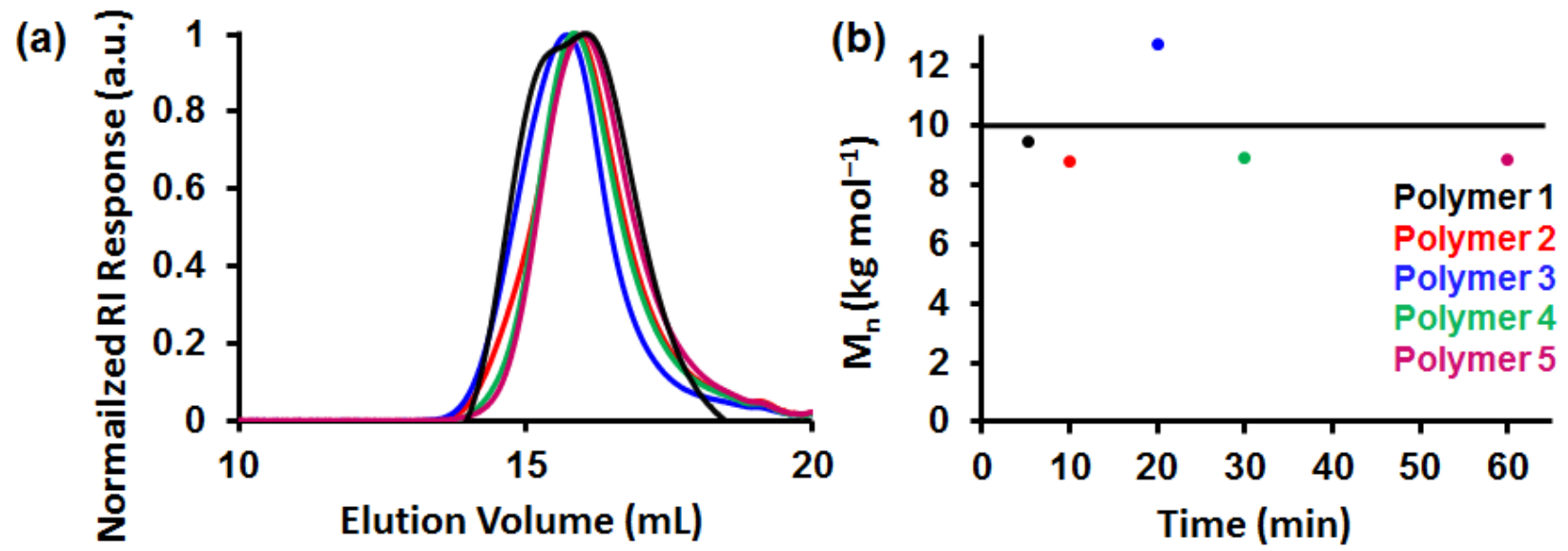
Figure 2. (a) SEC traces and (b) $M_{n} v s$. reaction time for Polymers 1-5. The solid line depicts the targeted $\mathrm{M}_{\mathrm{n}}$.

Improving dispersity. As the dispersity values recorded for Polymer 1-5 were relatively high compared to those obtained from living polymerization methods, i.e., $2.00 \pm 0.18$, we decided to further optimize the procedure based on the hypothesis that at $-20{ }^{\circ} \mathrm{C}$, the rate of initiation using $n$-BuLi could be slower than the rate of propagation. To examine this, we carried out two more polymerization experiments with similar feed molar ratios, i.e., $\mathrm{EtG} / n$-BuLi $=200$, but we combined $n$-BuLi and EtG at -78 and $20{ }^{\circ} \mathrm{C}$ (Polymers 6-7 respectively in Table 1). The SEC analysis showed that Polymers 6 and 7 had similar DP ${ }_{n}$ values, i.e., 196 and 198, consistent with the feed molar ratio. However, a very high $\oslash$ of 3.91 was obtained for Polymer 6 whereas an improved $Ð$ of 1.47 was obtained for Polymer 7. This result suggested that initiation using $n$-BuLi could be rate limiting at $-78{ }^{\circ} \mathrm{C}$, and the procedure used for Polymer 7 was selected as the optimized method for our polymerizations experiments.

Different alkyllithium reagents. Following our optimized polymerization method, two more polymerization experiments were carried out using PhLi and $t$-BuLi (Polymers 8-9 respectively in Table 1). The comparison of $\mathrm{DP}_{\mathrm{n}}$ and $Ð$ values recorded for Polymers 8 and 9 with those recorded for Polymer 7 revealed that there were no major differences in the performance of $n$ $\mathrm{BuLi}$, PhLi, and $t$-BuLi in controlling the polymerization.

Length-control experiments using n-BuLi. A set of five anionic polymerizations were conducted to further study the ability of alkyllithium reagents to control the $\mathrm{DP}_{\mathrm{n}}$ of PEtG by the variation of feed molar ratios, i.e., EtG/n-BuLi: 50, 100, 200, 400, and 600 (Polymers 10-14 in Table 1). Again, we characterized the unpurified polymers by SEC to evaluate the method. The first emerging trends were a decrease in elution times and an increase in the corresponding $\mathrm{DP}_{\mathrm{n}}$ by 
increasing the feed molar ratios (Figure 3a-b). However, the latter trend deviated from the ideal behavior when $\mathrm{EtG} / n$-BuLi ratios increased above 200. A possible explanation is that the polymerization was not reaching high EtG conversions for Polymers 13-14. However, this was ruled out when the crude polymerization mixtures were characterized by ${ }^{1} \mathrm{H}$ NMR spectroscopy and only very small amounts of EtG were identified, i.e., 4 and 2\% for Polymers 13 and 14 respectively.

(a)

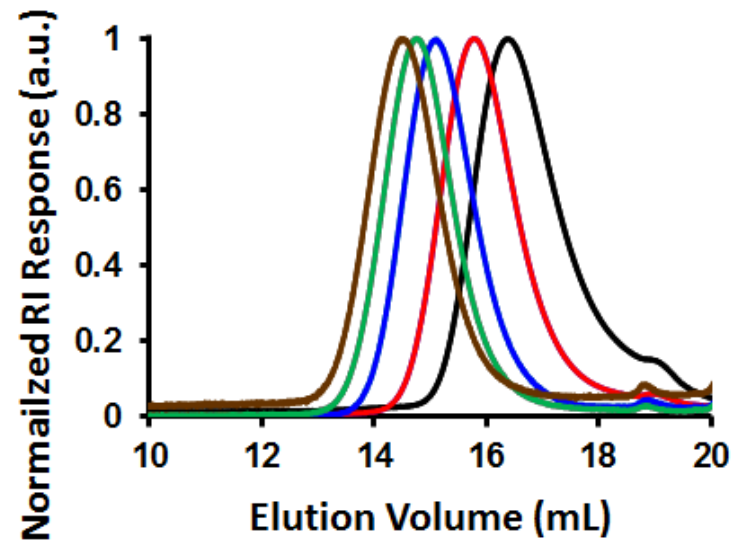

(c)

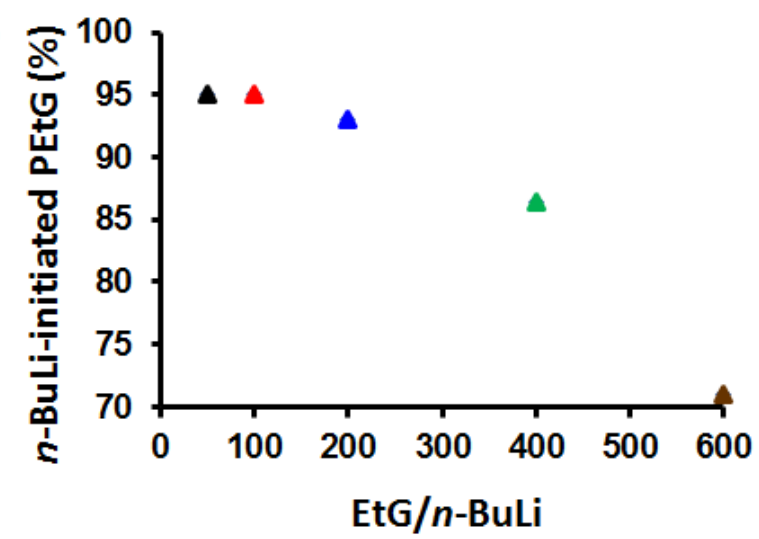

(e)<smiles>CCCCC(C)C(OC(=O)OCc1ccccc1)C(=O)OCC</smiles>

$n$-BuLi-initiated PEtG

Major product (b)

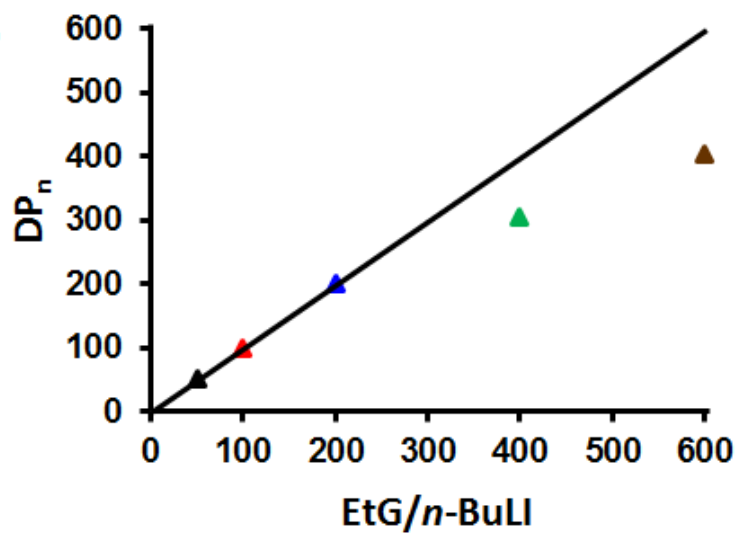

(d)

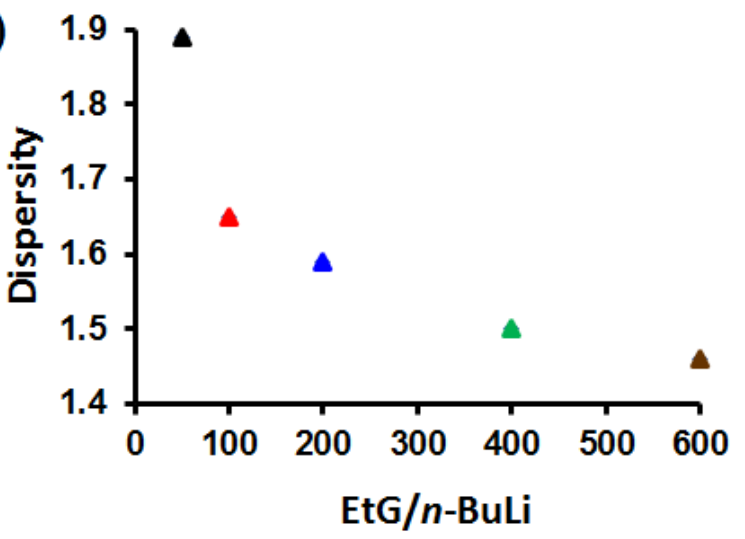

Hydrate-initiated PEtG Minor product 
Figure 3. (a)-(d) SEC data for Polymers 10-14: (a) SEC traces, (b) DP $v s$. feed molar ratios (EtG/n-BuLi), (c) n-BuLi-initiated PEtGs (\%) vs. feed molar ratios, (d) $Ð$ vs. feed molar ratios, and (e) structures of $n$-BuLi-initiated and hydrate-initiated PEtGs.

Another possibility for the deviation in obtained $\mathrm{DP}_{\mathrm{n}}$ from the theoretical $\mathrm{DP}_{\mathrm{n}}$ was the initiation by EtG hydrate species when very small amounts of $n$-BuLi were used to obtain high $\mathrm{EtG} / n$-BuLi ratios. Here it must be noted that we performed all manipulations under very rigorous conditions to keep our reagents/solvent/glassware dry. However, a 100\% water-free condition does not exist. For many aldehydes, hydrate species are reported to be always present, ${ }^{42,50,53}$ and it is conceivable that EtG hydrate distills at low levels with the desired monomer or that it is generated upon the reaction of distilled EtG with trace water present before or during polymerization. Hydrates have hydroxyl groups which can react with $n$-BuLi molecules and afford alkoxide initiators. Hence, when the number of $n$-BuLi molecules was much higher than that of hydrate, e.g., Polymers 10-12, $n$-BuLi was the dominant initiator and the hydrate initiator species were present in negligible amounts. Another extreme is when $n$-BuLi molecules are completely quenched by hydrate species (EtG/n-BuLi is very high) and control of molar mass is completely lost. We postulate that for Polymers 13-14 the concentration of hydrate species was relatively high enough to cause a noticeable deviation from the predicted $\mathrm{DP}_{\mathrm{n}}$ values, but their amount was not enough to fully quench $n$-BuLi molecules because the recorded molecular weights still increased from Polymer 13 to Polymer 14.

To further study the hypothesis regarding hydrate initiation, we purified Polymers 10-14 and characterized them by ${ }^{1} \mathrm{H}$ NMR spectroscopy for end-group analysis. As representative examples, the ${ }^{1} \mathrm{H}$ NMR spectra of purified Polymers $\mathbf{1 0}$ and $\mathbf{1 4}$ are shown in Figure S6 and S7. 
Based on our hypothesis, our method produces mixtures of alkyllithium-initiated PEtGs, which have one $n$-butyl and one benzyl carbonate end-cap, and hydrate-initiated PEtGs, which have two benzyl carbonate end-caps. $\mathrm{CH}_{3}$ groups of $n$-Bu end-groups appeared in all ${ }^{1} \mathrm{H}$ NMR spectra at $c a$. 0.88 ppm while the other $\mathrm{CH}_{2}$ groups of $n$-Bu could not be observed due to overlapping with peaks associated with the repeating units. Peaks corresponding to the benzyl carbonate were observed at ca. 5.2 and $7.3 \mathrm{ppm}$ corresponding to the benzylic protons and the aromatic protons, respectively. The percentage of alkyllithium-initiated PEtGs for Polymer 10-14 were calculated to be 95, 95, 93,86 , and $71 \%$, respectively (Figure $3 \mathrm{c}$, see SI for the calculation). This trend is clearly consistent with our hypothesis that hydrate initiation becomes important mainly at high $\mathrm{EtG} / n$-BuLi ratios. The last emerging trend was the decrease of dispersity with increasing EtG/n-BuLi ratios (Figure 3d). This can likely be explained by the differences in the rate of initiation/propagation or the higher possibility of the undesirable transesterification reaction of $n$-BuLi with ethyl ester groups at higher $n-\mathrm{BuLi} / \mathrm{EtG}$ ratios.

Characterization of anionically-produced PEtG. To study the properties of anionicallyproduced PEtGs, Polymer 7 was selected as a representative example. After purification, it was characterized using multinuclear NMR spectroscopy, SEC, TGA, and DSC (Table S2 and Figures S8, S9, and 4). Consistent with the PEtG produced by NEt 3 -mediated polymerization, the polymer gave rise to broad peaks associated with $\mathrm{CH}, \mathrm{CH}_{2}$, and $\mathrm{CH}_{3}$ at $c a .5 .5,4.2$, and 1.2 ppm respectively in the ${ }^{1} \mathrm{H}$ NMR spectrum. In addition, phenyl, benzyl, and $\mathrm{CH}_{3}$ (from $n$-Bu) protons of end-groups appeared at $c a .7 .3,5.2$, and $0.88 \mathrm{ppm}$, respectively (Figure S8). The percentage of alkyllithiuminitiated PEtG was calculated to be $67 \%$. It can be noted that $67 \%$ is lower than $93 \%$ obtained for Polymer 12 despite their similar DP values, as they were prepared from different distilled monomer batches, highlighting the high importance of monomer purity. In the ${ }^{13} \mathrm{C}\left\{{ }^{1} \mathrm{H}\right\}$ NMR spectrum, 
repeating units gave rise to peaks associated with $\mathrm{CO}, \mathrm{CH}, \mathrm{CH}_{2}$, and $\mathrm{CH}_{3}$ at $c a .165,93,62$, and $14 \mathrm{ppm}$ respectively. In addition, phenyl groups appeared at $c a .128 \mathrm{ppm}$ but $\mathrm{PhCH}_{2}$ and $n$-Buassociated peaks could not be observed due to their low intensity (Figure S9). SEC analysis showed that one precipitation into methanol was sufficient to afford a PEtG with a relatively low dispersity, i.e., $Đ=1.28$ (Table S2).

In TGA, Polymer 7 displayed an onset of degradation at $217^{\circ} \mathrm{C}$ and fully degraded at $c a$. $300{ }^{\circ} \mathrm{C}$ (Figure 4a). The degradation behavior was in accord with that reported for benzyl carbonate-end-capped PEtGs prepared using $\mathrm{NEt}_{3}$-mediated polymerization methods. ${ }^{47}$ This suggested that the high thermal stability of $n$-butyl groups did not affect the $\mathrm{T}_{\mathrm{o}}$ because the thermal stability of Polymer 7 was limited by the lower thermal stability of benzyl carbonate end-cap and backbone functional groups. DSC studies revealed a $\mathrm{T}_{\mathrm{g}}$ at $-5^{\circ} \mathrm{C}$ and again it was consistent with literature values. This implies that our anionically-produced PEtG is structurally similar to conventionally-produced PEtGs and the nature of $n$-Bu groups did not affect the interactions between the polymer chains (Figure $4 b$ ).
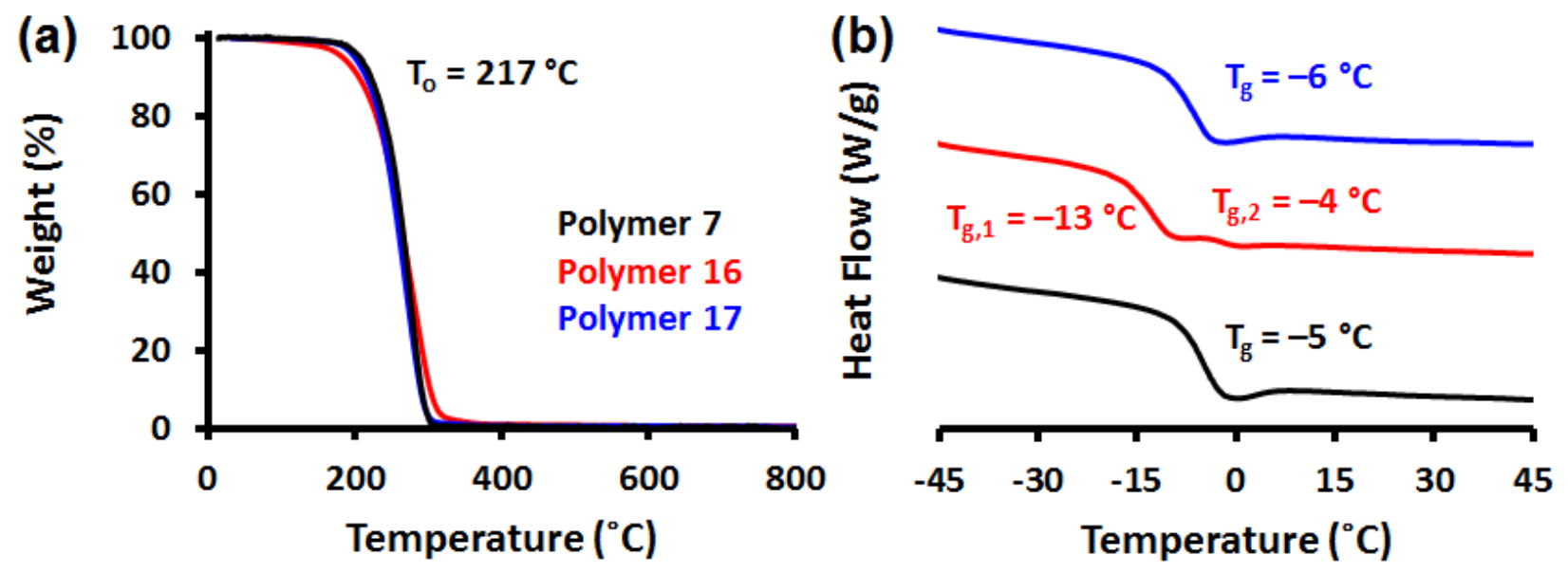

Figure 4. (a) TGA traces and (b) DSC thermograms of Polymers 7, 16, and 17. 
Alkoxide initiators. The alkyllithium reagents employed in this work provided the capacity to control the size of PEtGs but they are not functional end-groups. Hence, we lithiated propargyl alcohol and PEG diol to investigate the initiating properties of alkoxide species and to demonstrate that our method allows the use of various functional anionic species for PEtG synthesis.

Propargyl alkoxide. Propargyl alcohol was selected for the installation of an alkyne group which could be later exploited for click reactions and the preparation of copolymers or composites containing PEtGs. To prepare the alkoxide, one equivalent of $n$-BuLi was added to a toluene solution of propargyl alcohol and the resulting solution was stirred for 10 min before the addition of EtG. The polymerization and end-capping were conducted following our optimized method (Scheme 4).

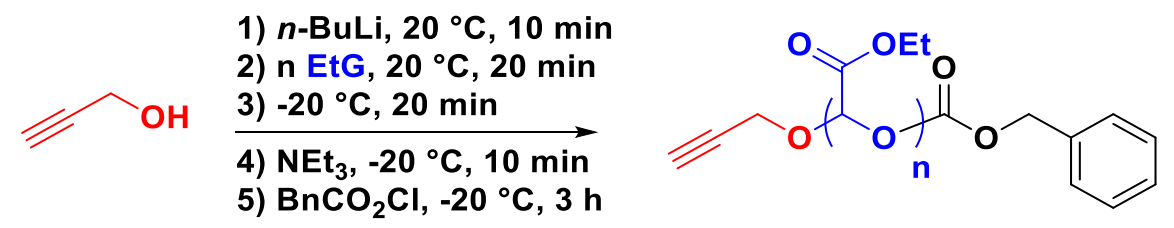

Scheme 4. Polymerization of EtG using lithiated propargyl alcohol.

The crude PEtG was characterized by SEC, which showed that the recorded $\mathrm{DP}_{\mathrm{n}}$ was slightly lower than the EtG/alkoxide ratio, i.e., 93 vs. 100 (entry 1 in Table 2). This minor deviation was likely observed because the combination of alkoxides with alcohols (from EtG hydrates) can increase the number of initiating species as they can activate each other via proton exchange. The crude PEtG was precipitated into methanol and then dried under vacuum to afford Polymer $\mathbf{1 5}$ in $60 \%$ yield. SEC analysis confirmed that the purification improved the dispersity by removal of the low-molar mass fraction of PEtGs $\left(\mathrm{M}_{\mathrm{n}}=14,000 \mathrm{~g} / \mathrm{mol}, \mathrm{M}_{\mathrm{w}}=17,000 \mathrm{~g} / \mathrm{mol}, Ð=1.21, \mathrm{DP}_{\mathrm{n}}=137\right)$. In the ${ }^{1} \mathrm{H}$ NMR spectrum, the terminal $\mathrm{CH}$ of propargyl group appeared at $c a .2 .5$ ppm while its 
$\mathrm{CH}_{2}$ group could not be observed due to overlapping with the $\mathrm{CH}_{2}$ peak of repeating units (Figure S10). This confirmed that propargyl alkoxide served as an initiator. However, the fact that $\mathrm{CH}_{3}$ groups of $n$-Bu were also observed at $c a .0 .88 \mathrm{ppm}$ suggested that 10 min was not sufficient for converting propargyl alcohol to the corresponding alkoxide. The comparison of the intensities of the $\mathrm{CH}_{3}$ (from $n$-Bu) and $\mathrm{CH}$ (from propargyl) signals revealed that the propargyl-initiated PEtG/nBu-initiated PEtG ratio was 55/45.

Table 2. SEC characterization data for alkoxide-initiated PEtGs.

\begin{tabular}{|c|c|c|c|c|c|c|c|c|}
\hline Name & Initiator & $\begin{array}{l}\text { Lithiation } \\
\text { Time } \\
\text { (min) }\end{array}$ & $\begin{array}{l}\text { Initiation } \\
\text { Time } \\
\text { (min) }\end{array}$ & $\begin{array}{c}M_{n} \\
(\mathrm{~g} / \mathrm{mol})\end{array}$ & $\begin{array}{c}M_{w} \\
(\mathrm{~g} / \mathrm{mol})\end{array}$ & $\boldsymbol{\theta}$ & $\mathbf{D P}_{\mathbf{n}}$ & EtG/Ini. \\
\hline $\begin{array}{c}\text { Polymer } \\
15\end{array}$ & $\begin{array}{c}\text { Propargyl- } \\
\mathrm{OH} / n- \\
\mathrm{BuLi}\end{array}$ & 10 & 30 & 9,500 & 13,250 & 1.39 & 93 & 100 \\
\hline $\begin{array}{c}\text { Polymer } \\
16\end{array}$ & $\begin{array}{c}\mathrm{PEG} / n- \\
\mathrm{BuLi}\end{array}$ & 60 & 120 & 7,500 & 11,500 & 1.57 & 73 & 100 \\
\hline $\begin{array}{c}\text { Polymer } \\
17\end{array}$ & $\begin{array}{c}\mathrm{PEG} / n- \\
\mathrm{BuLi}\end{array}$ & 60 & 120 & 22,750 & 34,500 & 1.52 & 223 & 400 \\
\hline
\end{tabular}

PEG dialkoxides. High molecular weight alcohols can serve as macroinitiators for the direct synthesis of copolymers. Here a PEG diol $\left(\mathrm{M}_{\mathrm{n}}=600 \mathrm{~g} / \mathrm{mol}\right)$ was selected to study the reactivity because PEGs are ubiquitous building blocks of amphiphilic copolymers. ${ }^{54}$ Like propargyl alcohol, HO-PEG-OH was exposed to 2 equiv. of $n$-BuLi to create the dialkoxide. However, the time of lithiation was increased to $60 \mathrm{~min}$ and different feed molar ratios were employed, i.e., $\mathrm{EtG} / \mathrm{RO}^{-}$: 
100 and 400. In addition, to account for the relatively lower nucleophilic activity of the lithiated PEGs, the reaction time of EtG and dialkoxide was increased to $2 \mathrm{~h}$ (Scheme 5). SEC analysis of the unpurified polymers showed that consistent with the behavior of propargyl alkoxide, PEG dialkoxides produced polymers with $\mathrm{DP}_{\mathrm{n}}$ lower than expected (entries $2-3$ in Table 2).

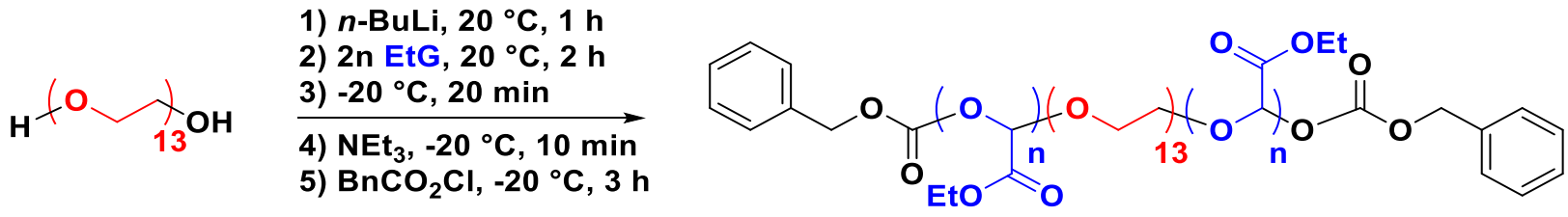

Scheme 5. Polymerization of EtG using lithiated PEGs.

The precipitation of the copolymers into methanol lowered the dispersity values, i.e., $c a$. 1.30, and adjusted their $\mathrm{M}_{\mathrm{n}}$ to 11,500 and 32,250 g/mol for Polymer 16 and 17, respectively (Figure S13 and Table S2). The purified samples were characterized using ${ }^{1} \mathrm{H}$ NMR spectroscopy, TGA, and DSC. In their NMR spectra, Polymers 16 and 17 had peaks associated with PEtG block (at ca. 5.5, 4.2, and $1.2 \mathrm{ppm}$ ), PEG block (at ca. $3.6 \mathrm{ppm}$ ), and benzyl carbonate end groups (ca. 7.4 and $5.2 \mathrm{ppm}$ ) (Figures S11 and S12). No peak corresponding to $n$-Bu (ca. $0.88 \mathrm{ppm}$ ) was observed, implying that all $n$-BuLi molecules were reacted before the initiation step and alkoxide species were the dominant initiators. As we expected to see traces of both hydrate-initiated homopolymers and PEG-initiated triblock copolymers in the ${ }^{1} \mathrm{H}$ NMR spectra, we calculated the triblock copolymer fractions (see SI for the equations). The calculated ratios were 59 and 58\%, respectively for Polymers 16 and 17. TGA showed that Polymers 16 and $\mathbf{1 7}$ have similar thermal stability to PEtG homopolymers end-capped with benzyl carbonate groups (Figure 4a). Comparable with the thermal behavior of PEtG homopolymers, Polymer 17 revealed a $T_{g}$ at -6 ${ }^{\circ} \mathrm{C}$ in its DSC thermogram, while Polymer 16 exhibited two glass transition temperatures at -13 and $-4{ }^{\circ} \mathrm{C}$. This observation reflects the fact that in Polymer 16 the portion of PEG block was 
large enough to give rise to the second glass transition, while for Polymers 17 such a feature cannot be seen due to the negligible mass fraction of the PEG block relative to the PEtG block (Figure 4b).

\section{CONCLUSIONS}

In conclusion, a highly reproducible purification method for EtG was developed and the high quality of the monomers were confirmed through the preparation of high molecular weight PEtGs. After analysis of the monomer-polymer equilibrium using VT ${ }^{1} \mathrm{H}$ NMR spectroscopy, the polymerization temperature was selected to be $-20{ }^{\circ} \mathrm{C}$. Kinetic studies demonstrated that the rate of polymerization was very fast, even at $-20{ }^{\circ} \mathrm{C}$. In comparison, the rate of initiation at low temperatures was relatively slow. Hence, the initiators were introduced at $20^{\circ} \mathrm{C}$. SEC analysis confirmed the abilities of $n$-BuLi, PhLi, and $t$-BuLi to control the lengths of PEtGs. Characterization of PEtGs prepared during size-control experiments using $n$-BuLi revealed that up to a threshold $\left(\mathrm{DP}_{\mathrm{n}} \leq 200\right)$, alkyllithium reagents can accurately determine the PEtG length but above that the interference of residual hydrate species causes a negative deviation from the targeted $\mathrm{DP}_{\mathrm{n}} \mathrm{s}$. In contrast, lithiated alcohols exhibited negative deviations regardless of the targeted $\mathrm{DP}_{\mathrm{n}} \mathrm{s}$. These interferences resulted in the formation of minor hydrate-initiated PEtG fractions, but their portions drastically decreased as the EtG/initiator ratio was decreased. In addition, all employed

alkyllithium and functional alkoxide initiators produced the targeted materials and confirmed the versatility of our method for the synthesis of PEtGs with predefined size and termini. 
Supporting Information. Calculations for end-group analysis; pictures of EtG distillation setup; ${ }^{1} \mathrm{H},{ }^{13} \mathrm{C}\left\{{ }^{1} \mathrm{H}\right\}$, and ${ }^{31} \mathrm{P}\left\{{ }^{1} \mathrm{H}\right\}$ NMR spectra; and SEC data for purified polymers (pdf).

\section{AUTHOR INFORMATION}

\section{Corresponding Author}

*E-mail egillie@uwo.ca (E.R.G.).

\section{Notes}

The authors declare no competing financial interest.

\section{ACKNOWLEDGMENTS}

The authors thank the Natural Sciences and Engineering Research Council of Canada (Strategic Partnership Grant 478981) for funding this work.

\section{REFERENCES}

(1) Roth, M. E.; Green, O.; Gnaim, S.; Shabat, D. Dendritic, Oligomeric, and Polymeric SelfImmolative Molecular Amplification. Chem. Rev. 2016, 116, 1309-1352.

(2) Peterson, G. I.; Larsen, M. B.; Boydston, A. J. Controlled Depolymerization: StimuliResponsive Self-Immolative Polymers. Macromolecules 2012, 45, 7317-7328. 
(3) Esser-Kahn, A. P.; Sottos, N. R.; White, S. R.; Moore, J. S. Programmable Microcapsules from Self-Immolative Polymers. J. Am. Chem. Soc. 2010, 132, 10266-10268.

(4) Wang, W.; Alexander, C. Self-Immolative Polymers. Angew. Chem. Int. Ed. 2008, 47, 7804-7806.

(5) Sagi, A.; Weinstain, R.; Karton, N.; Shabat, D. Self-Immolative Polymers. J. Am. Chem. Soc. 2008, 130, 5434-5435.

(6) Manouras, T.; Vamvakaki, M. Field Responsive Materials: Photo-, Electro-, Magneticand Ultrasound-sensitive Polymers. Polym. Chem. 2017, 8, 74-96.

(7) Kaitz, J. A.; Lee, O. P.; Moore, J. S. Depolymerizable Polymers: Preparation, Applications, and Future Outlook. MRS Commun. 2015, 5, 191-204.

(8) Jochum, F. D.; Theato, P. Temperature- and Light-responsive Smart Polymer Materials. Chem. Soc. Rev. 2013, 42, 7468-7483.

(9) Zhai, L. Stimuli-responsive Polymer Films. Chem. Soc. Rev. 2013, 42, 7148-7160.

(10) Kharkar, P. M.; Kiick, K. L.; Kloxin, A. M. Designing Degradable Hydrogels for Orthogonal Control of Cell Microenvironments. Chem. Soc. Rev. 2013, 42, 7335-7372. (11) Zhuang, J.; Gordon, M. R.; Ventura, J.; Li, L.; Thayumanavan, S. Multi-stimuli Responsive Macromolecules and Their Assemblies. Chem. Soc. Rev. 2013, 42, 7421-7435. (12) Steinkoenig, J.; Zieger, M. M.; Mutlu, H.; Barner-Kowollik, C. Dual-Gated Chain Shattering Based on Light Responsive Benzophenones and Thermally Responsive Diels-Alder Linkages. Macromolecules 2017, 50, 5385-5391.

(13) Olejniczak, J.; Nguyen Huu, V. A.; Lux, J.; Grossman, M.; He, S.; Almutairi, A. Lighttriggered Chemical Amplification to Accelerate Degradation and Release from Polymeric Particles. Chem. Commun. 2015, 51, 16980-16983. 
(14) de Gracia Lux, C.; McFearin, C. L.; Joshi-Barr, S.; Sankaranarayanan, J.; Fomina, N.;

Almutairi, A. Single UV or Near IR Triggering Event Leads to Polymer Degradation into Small Molecules. ACS Macro Lett. 2012, 1, 922-926.

(15) Peterson, G. I.; Church, D. C.; Yakelis, N. A.; Boydston, A. J. 1,2-Oxazine Linker as a Thermal Trigger for Self-immolative Polymers. Polymer 2014, 55, 5980-5985.

(16) Binauld, S.; Stenzel, M. H. Acid-degradable Polymers for Drug Delivery: a Decade of Innovation. Chem. Commun. 2013, 49, 2082-2102.

(17) Mutlu, H.; Barner-Kowollik, C. Green Chain-shattering Polymers Based on a Selfimmolative Azobenzene Motif. Polym. Chem. 2016, 7, 2272-2279.

(18) Li, Y.; Liu, G.; Wang, X.; Hu, J.; Liu, S. Enzyme-Responsive Polymeric Vesicles for Bacterial-Strain-Selective Delivery of Antimicrobial Agents. Angew. Chem. Int. Ed. 2016, 55, $1760-1764$.

(19) Deng, Z.; Qian, Y.; Yu, Y.; Liu, G.; Hu, J.; Zhang, G.; Liu, S. Engineering Intracellular Delivery Nanocarriers and Nanoreactors from Oxidation-Responsive Polymersomes via Synchronized Bilayer Cross-Linking and Permeabilizing Inside Live Cells. J. Am. Chem. Soc. 2016, $138,10452-10466$.

(20) Dewit, M. A.; Beaton, A.; Gillies, E. R. A Reduction Sensitive Cascade Biodegradable Linear Polymer. J. Polym. Sci., Part A: Polym. Chem. 2010, 48, 3977-3985.

(21) DiLauro, A. M.; Lewis, G. G.; Phillips, S. T. Self-Immolative Poly(4,5dichlorophthalaldehyde) and its Applications in Multi-Stimuli-Responsive Macroscopic Plastics. Angew. Chem. Int. Ed. 2015, 54, 6200-6205. 
S. T. Self-Powered Microscale Pumps Based on Analyte-Initiated Depolymerization Reactions. Angew. Chem. Int. Ed. 2012, 51, 2400-2404.

(23) Liu, G.; Wang, X.; Hu, J.; Zhang, G.; Liu, S. Self-immolative Polymersomes for Highefficiency Triggered Release and Programmed Enzymatic Reactions. J. Am. Chem. Soc. 2014, $136,7492-7497$.

(24) Robbins, J. S.; Schmid, K. M.; Phillips, S. T. Effects of Electronics, Aromaticity, and Solvent Polarity on the Rate of Azaquinone-Methide-Mediated Depolymerization of Aromatic Carbamate Oligomers. J. Org. Chem. 2013, 78, 3159-3169.

(25) DeWit, M. A.; Gillies, E. R. A Cascade Biodegradable Polymer Based on Alternating Cyclization and Elimination Reactions. J. Am. Chem. Soc. 2009, 131, 18327-18334.

(26) Wang, F.; Diesendruck, C. E. Polyphthalaldehyde: Synthesis, Derivatives, and Applications. Macromol. Rapid Commun. 2018, 39, 1700519.

(27) Feinberg, A. M.; Hernandez, H. L.; Plantz, C. L.; Mejia, E. B.; Sottos, N. R.; White, S. R.; Moore, J. S. Cyclic Poly(phthalaldehyde): Thermoforming a Bulk Transient Material. ACS Macro Lett. 2018, 7, 47-52.

(28) Schwartz, J. M.; Engler, A.; Phillips, O.; Lee, J.; Kohl, P. A. Determination of Ceiling Temperature and Thermodynamic Properties of Low Ceiling Temperature Polyaldehydes. $J$. Polym. Sci., Part A: Polym. Chem. 2018, 56, 221-228.

(29) Park, C. W.; Kang, S. K.; Hernandez, H. L.; Kaitz, J. A.; Wie, D. S.; Shin, J.; Lee, O. P.; Sottos, N. R.; Moore, J. S.; Rogers, J. A.; White, S. R. Thermally Triggered Degradation of Transient Electronic Devices. Adv. Mater. 2015, 27, 3783-3788. 
(30) Kaitz, J. A.; Diesendruck, C. E.; Moore, J. S. End Group Characterization of

Poly(phthalaldehyde): Surprising Discovery of a Reversible, Cationic Macrocyclization Mechanism. J. Am. Chem. Soc. 2013, 135, 12755-12761.

(31) Seo, W.; Phillips, S. T. Patterned Plastics That Change Physical Structure in Response to Applied Chemical Signals. J. Am. Chem. Soc. 2010, 132, 9234-9235.

(32) Knoll, A. W.; Pires, D.; Coulembier, O.; Dubois, P.; Hedrick, J. L.; Frommer, J.; Duerig, U. Probe-Based 3-D Nanolithography Using Self-Amplified Depolymerization Polymers. $A d v$. Mater. 2010, 22, 3361-3365.

(33) Lewis, G. G.; Robbins, J. S.; Phillips, S. T. Phase-Switching Depolymerizable Poly(carbamate) Oligomers for Signal Amplification in Quantitative Time-Based Assays. Macromolecules 2013, 46, 5177-5183.

(34) Gnaim, S.; Shabat, D. Self-Immolative Chemiluminescence Polymers: Innate Assimilation of Chemiexcitation in a Domino-like Depolymerization. J. Am. Chem. Soc. 2017, 139, 10002-10008.

(35) DiLauro, A. M.; Zhang, H.; Baker, M. S.; Wong, F.; Sen, A.; Phillips, S. T. Accessibility of Responsive End-Caps in Films Composed of Stimuli-Responsive, Depolymerizable Poly(phthalaldehydes). Macromolecules 2013, 46, 7257-7265.

(36) Coulembier, O.; Knoll, A.; Pires, D.; Gotsmann, B.; Duerig, U.; Frommer, J.; Miller, R. D.; Dubois, P.; Hedrick, J. L. Probe-Based Nanolithography: Self-Amplified Depolymerization Media for Dry Lithography. Macromolecules 2010, 43, 572-574.

(37) Ito, H.; Willson, C. G. Chemical Amplification in the Design of Dry Developing Resist Materials. Polym. Eng. Sci. 1983, 23, 1012-1018. 
(38) Liu, G.; Zhang, G.; Hu, J.; Wang, X.; Zhu, M.; Liu, S. Hyperbranched Self-immolative Polymers (hSIPs) for Programmed Payload Delivery and Ultrasensitive Detection. J. Am. Chem. Soc. 2015, 137, 11645-11655.

(39) Fan, B.; Gillies, E. R. Poly(ethyl glyoxylate)-Poly(ethylene oxide) Nanoparticles:

Stimuli-Responsive Drug Release via End-to-End Polyglyoxylate Depolymerization. Mol.

Pharm. 2017, 14, 2548-2559.

(40) Fan, B.; Yardley, R.; Trant, J. F.; Borecki, A.; Gillies, E. R. Tuning the Hydrophobic Cores of Self-immolative Polyglyoxylate Assemblies. Polym. Chem. 2018, 9, 2601-2610.

(41) Gambles, M. T.; Fan, B.; Borecki, A.; Gillies, E. R. Hybrid Polyester Self-immolative Polymer Nanoparticles for Controlled Drug Release. ACS Omega 2018, 3, 5002-5011.

(42) Burel, F.; Rossignol, L.; Pontvianne, P.; Hartman, J.; Couesnon, N.; Bunel, C. Synthesis and Characterization of Poly(ethyl glyoxylate) - A New Potentially Biodegradable Polymer. $e$ Polymers 2003, 3, 407.

(43) Belloncle, B.; Burel, F.; Bunel, C. Synthesis and Degradation of Poly(ethyl glyoxylate). In Polymer Degradation and Performance, Celina, M. C.; Wiggins, J. S.; Billingham, N. C., Eds. American Chemical Society: Washington, 2009; pp 41-51.

(44) Belloncle, B.; Burel, F.; Oulyadi, H.; Bunel, C. Study of the in vitro Degradation of Poly(ethyl glyoxylate). Polym. Degrad. Stab. 2008, 93, 1151-1157.

(45) Fan, B.; Gillies, E. R. Self-Immolative Polymers. Encycl. Polym. Sci. Technol. 2015, 135.

(46) Belloncle, B.; Bunel, C.; Menu-Bouaouiche, L.; Lesouhaitier, O.; Burel, F. Study of the Degradation of Poly(ethyl glyoxylate): Biodegradation, Toxicity and Ecotoxicity Assays. $J$. Polym. Environ. 2012, 20, 726-731. 
(47) Fan, B.; Trant, J. F.; Wong, A. D.; Gillies, E. R. Polyglyoxylates: A Versatile Class of Triggerable Self-Immolative Polymers from Readily Accessible Monomers. J. Am. Chem. Soc. 2014, 136, 10116-10123.

(48) Fan, B.; Trant, J. F.; Gillies, E. R. End-Capping Strategies for Triggering End-to-End Depolymerization of Polyglyoxylates. Macromolecules 2016, 49, 9309-9319.

(49) Fan, B.; Salazar, R.; Gillies, E. R. Depolymerization of Trityl End-Capped Poly(Ethyl Glyoxylate): Potential Applications in Smart Packaging. Macromol. Rapid Commun. 2018, 39, 1800173.

(50) Kaitz, J. A.; Diesendruck, C. E.; Moore, J. S. Divergent Macrocyclization Mechanisms in the Cationic Initiated Polymerization of Ethyl Glyoxylate. Macromolecules 2014, 47, 36033607.

(51) Vogl, O. Addition Polymers of Aldehydes. J. Polym. Sci., Part A: Polym. Chem. 2000, 38, 2293-2299.

(52) Dainton, F. S.; Ivin, K. J. Reversibility of the Propagation Reaction in Polymerization Processes and its Manifestation in the Phenomenon of a 'Ceiling Temperature'. Nature 1948, $162,705-707$.

(53) Köstler, S. Polyaldehydes: Homopolymers, Block Copolymers and Promising Applications. Polym. Int. 2012, 61, 1221-1227.

(54) Knop, K.; Hoogenboom, R.; Fischer, D.; Schubert, U. S.,Poly(ethylene glycol) in Drug Delivery: Pros and Cons as Well as Potential Alternatives. Angew. Chem. Int. Ed. 2010, 49, $6288-6308$. 